\title{
Insula's functional connectivity with ventromedial prefrontal cortex mediates the impact of trait alexithymia on state tobacco craving
}

\author{
Matthew T. Sutherland, \\ Department of Psychology, Florida International University, Miami, FL, USA \\ Neuroimaging Research Branch, National Institute on Drug Abuse, Intramural Research Program, \\ $\mathrm{NIH} / \mathrm{DHHS}$, Baltimore, MD, USA
}

\begin{abstract}
Allison J. Carroll, Neuroimaging Research Branch, National Institute on Drug Abuse, Intramural Research Program, $\mathrm{NIH} / \mathrm{DHHS}$, Baltimore, MD, USA
\end{abstract}

\section{Betty Jo Salmeron,}

Neuroimaging Research Branch, National Institute on Drug Abuse, Intramural Research Program, $\mathrm{NIH} / \mathrm{DHHS}$, Baltimore, MD, USA

Thomas J. Ross, and

Neuroimaging Research Branch, National Institute on Drug Abuse, Intramural Research Program, $\mathrm{NIH} / \mathrm{DHHS}$, Baltimore, MD, USA

\section{Elliot A. Stein}

Neuroimaging Research Branch, National Institute on Drug Abuse, Intramural Research Program, $\mathrm{NIH} / \mathrm{DHHS}$, Baltimore, MD, USA

\begin{abstract}
Rationale-Alexithymia is a personality trait characterized by difficulty indentifying and describing subjective emotional experiences. Decreased aptitude in the perception, evaluation, and communication of affectively laden mental states has been associated with reduced emotion regulation, more severe drug craving in addicts, and structural/functional alterations in insula and anterior cingulate cortex (ACC). The insula and ACC represent sites of convergence between the putative neural substrates of alexithymia and those perpetuating cigarette smoking.
\end{abstract}

Objectives-We examined the interrelations between alexithymia, tobacco craving, and insula/ ACC neurocircuitry using resting-state functional connectivity (rsFC).

Methods-Overnight-deprived smokers $(n=24)$ and non-smokers $(n=20)$ completed six neuroimaging assessments on different days both in the absence of, and following, varenicline and/or nicotine administration. In this secondary analysis of data from a larger study, we assessed trait alexithymia and state tobacco craving using self-reports and examined the rsFC of bilateral insular subregions (anterior, middle, posterior) and dorsal ACC.

Results-Higher alexithymia in smokers predicted reduced rsFC strength between the right anterior insula (aI) and ventromedial prefrontal cortex (vmPFC). Higher alexithymia also

\footnotetext{
(C) Springer-Verlag Berlin Heidelberg (outside the USA) 2013

Department of Psychology, Florida International University, Deuxieme Maison, RM 295, 11299 S.W. 8th Street, Miami, FL 33199, USA, masuther@fiu.edu.

Conflicts of interest The authors declare no conflicts of interest.
} 
predicted more severe tobacco craving during nicotine withdrawal. Critically, the identified aIvmPFC circuit fully mediated this alexithymia-craving relation. That is, elevated alexithymia predicted decreased aI-vmPFC rsFC and, in turn, decreased aI-vmPFC rsFC predicted increased craving during withdrawal. A moderated mediation analysis indicated that this aI-vmPFC mediational effect was not observed following drug administration.

Conclusions-These results suggest that a weakened right aI-vmPFC functional circuit confers increased liability for tobacco craving during smoking abstinence. Individual differences in alexithymia and/or aI-vmPFC functional coupling may be relevant factors for smoking cessation success.

\section{Keywords}

Alexithymia; Craving; Nicotine; Varenicline; Resting-state functional connectivity; Insula; Ventromedial prefrontal cortex; fMRI

\section{Introduction}

Individuals differ in their abilities to perceive, process, and regulate subjective emotional experiences. Emotional responses often precipitate regulatory mechanisms and the conscious awareness of such states may facilitate optimal regulation strategies (Ochsner and Gross 2005). Alexithymia is a personality trait characterized by a diminished capacity to identify and describe affective states as well as an externally oriented cognitive style (Parker et al. 2008; Taylor and Bagby 2004). The alexithymia construct is regarded as a stable personality trait in both healthy and drug addicted individuals (de Timary et al. 2008; Tolmunen et al. 2011) and has been linked with serotonergic and catecholaminergic genotypic variability (Kano et al. 2012; Swart et al. 2011).

Alexithymic characteristics are indicative of deficiencies in the subjective awareness, cognitive processing, and optimal regulation of emotions (Chen et al. 2011; Pollatos and Gramann 2012; Swart et al. 2009). As several neuropsychiatric conditions can be characterized by maladaptive affect regulation and given associations with autism (Silani et al. 2008), posttraumatic stress disorder (Frewen et al. 2008), eating disorders (Miyake et al. 2012), and drug addiction (Speranza et al. 2004), alexithymia may represent a vulnerability and/or negative prognostic factor for multiple conditions (Ogrodniczuk et al. 2011; Taylor 2000). With respect to drug addiction, deficits in the cognitive processing and regulation of emotions may contribute to the onset, exacerbation, and/or maintenance of drug use via negative reinforcement mechanisms (Baker et al. 2004; Cheetham et al. 2010; Kun and Demetrovics 2010).

Accumulating evidence from individuals addicted to various drugs implicates alexithymia as a negative outcome predictor. For example, higher levels of alexithymia are indicative of quicker time to relapse and reduced treatment engagement in alcohol, cocaine, and polydrug abusers (Cleland et al. 2005; Keller et al. 1995; Loas et al. 1997b). Elevated alexithymia also predicts greater dependence, use severity, and compromised emotion regulation in alcoholics (Bruce et al. 2012; Stasiewicz et al. 2012; Thorberg et al. 2009). Craving, the strong subjective desire for a drug, is a particularly relevant clinical construct encompassing emotional and motivational phenomena that perpetuate drug use and precipitate relapse (Ferguson and Shiffman 2009). Emerging evidence connects increased alexithymia with more severe craving in alcoholics and methamphetamine addicts (Junghanns et al. 2005; Saladin et al. 2012; Thorberg et al. 2011), which may partly explain alexithymia's link with use severity and relapse propensity. Impaired awareness of emotional states and/or responsiveness to drug cues may contribute to reduced craving 
mitigation abilities (Goldstein et al. 2009). As such, elucidating the relations between alexithymia in cigarette smokers, tobacco craving, and importantly, the underlying neurocircuitry involved may provide insight into individual differences that could serve to expedite implementation of tailored cessation interventions.

Neuroimaging data support the conceptualization of alexithymia as a neuropsychological construct. Higher degrees of alexithymia are associated with altered structure/function in canonical emotion-related brain regions including, the insula, anterior cingulate cortex (ACC), ventromedial prefrontal cortex (vmPFC), and amygdala (Wingbermuhle et al. 2012). Structurally, alexithymia has been directly related to gray matter volume reductions in the insula, ACC, and vmPFC (Borsci et al. 2009; Paradiso et al. 2008). Similarly, poorer emotional intelligence and interoceptive awareness, indirect features of alexithymia (Baughman et al. 2011; Herbert et al. 2011), have been linked with gray matter reductions in right anterior insula (aI), dorsal ACC, and vmPFC (Critchley et al. 2004; Takeuchi et al. 2011). These alexithymia-related structural aberrations are paralleled by functional alterations most consistently observed in the insula and ACC during affective processing tasks (e.g., Kano et al. 2007; Moriguchi et al. 2007; Pouga et al. 2010; Reker et al. 2010; Silani et al. 2008).

The insula, ACC, and vmPFC represent critical sites of convergence between the neural substrates of alexithymia and those perpetuating cigarette smoking. Specifically, increased activity in these regions has been consistently observed following drug-related cue presentation and often correlates with subjective tobacco craving (Chase et al. 2011; Engelmann et al. 2012; Naqvi et al. 2007). Theoretical accounts suggest that interactions between the insula, ACC, and vmPFC underlie affective processes at multiple stages of the addiction cycle, particularly during drug withdrawal (Naqvi and Bechara 2010).

Neuroimaging evidence indicates that the insula is involved in monitoring homeostatically relevant bodily sensations (Craig 2009; Critchley et al. 2004) and that the vmPFC is involved in the processing and regulation of emotion (Foland-Ross et al. 2010; Kim et al. 2011). While the insula, ACC, and vmPFC appear to constitute critical nodes in the neurocircuitry underlying alexithymia and drug addiction, little is known about the circuitlevel interactions of these brain regions as a function of trait alexithymia or state tobacco craving.

Circuit-level interactions between brain regions can be investigated using resting-state functional connectivity ( $\mathrm{rsFC}$ ), the assessment of synchronized low-frequency fluctuations in the fMRI signal collected in the absence of explicit task demands. Such rsFC assessments have been increasingly employed (Fox and Raichle 2007) to interrogate functional circuits constrained to known neuroanatomical pathways (Greicius et al. 2009) including those associated with the insula and ACC (Cauda et al. 2011; Hong et al. 2009). With respect to the insula's functional organization, previous rsFC studies have identified three discernible subregions (anterior, middle, posterior) along a ventral-anterior to dorsal-posterior trajectory (Deen et al. 2011; Taylor et al. 2009). Parcellations of the insula using rsFC recapitulate those synthesized from anatomical and functional observations implicating the posterior insula (pI) in somatosensation and interoception, middle insula (mI) in cognitive and integration capacities, and aI in affective processing and subjective awareness (Craig 2009; Nieuwenhuys 2012). As such, we explored the influence of alexithymia on anterior, middle, and posterior insula's rsFC strength with other brain regions. Given the al's critical role in the processing and awareness of affective states (Craig 2010; Kurth et al. 2010), we first examined this subregion. We also explored the dorsal ACC's rsFC using bilateral "seed" regions. 
To probe the interrelations between alexithymia, craving, and rsFC, both abstinent smokers and nonsmokers completed six fMRI assessments. All participants were scanned under two general conditions: (1) in the absence of pharmacological manipulations (i.e., during nicotine withdrawal in smokers), and (2) after administration of varenicline and/or nicotine (four sessions), two modestly effective cessation aids that reduce withdrawal symptoms and tobacco craving in abstinent smokers. Assessment of smokers in both the absence and presence of these drug manipulations allowed us to determine if the relations between alexithymia, craving, and rsFC were specific to the withdrawn state. In this secondary analysis of data from a larger study (Sutherland et al. 2013b), we addressed three questions: (1) Does alexithymia predict individual differences in the functional coupling of the insula/ ACC with other brain regions in smokers and/or nonsmokers, particularly the aI. (2) Does alexithymia predict tobacco craving severity in smokers, particularly during withdrawal. (3) Do specific brain circuits mediate such an alexithymia-craving relation?

\section{Methods and materials}

\section{Participants}

In total, 24 cigarette smokers ( 12 females) and 20 nonsmokers ( 10 females) completed the study. We recruited daily smokers who reported smoking 10 or more cigarettes per day for a minimum of 2 years and nonsmokers who reported no history of daily cigarette use and no smoking within the preceding 2 years. Smokers were $36 \pm 10$ years of age (mean \pm SD), smoked $18 \pm 8$ cigarettes/day, reported daily cigarette use for $18 \pm 11$ years, and were moderately nicotine dependent (Fagerström scores: $5 \pm 2$; see Supplementary Information $[\mathrm{SI}]$ and Table $\mathrm{S} 1$ for participant details). As our nonsmokers were younger (30 \pm 7 years; $p=0.05$ ) than smokers, age was included as a covariate in group comparisons. Data from one male smoker and one male nonsmoker were excluded due to excessive head motion during MRI scanning. Before study onset, participants gave written informed consent in accordance with the National Institute on Drug Abuse Intramural Research Program Institutional Review Board.

\section{Design and drugs}

Both smokers and nonsmokers completed six fMRI assessments on different days in a twodrug, double-blind, placebo-controlled study. At three points during a varenicline administration regime (pre-pill, varenicline pill, placebo pill), participants were scanned twice, once each wearing a nicotine or placebo patch. After two initial pre-pill sessions, participants were administered varenicline (17.0 \pm 4.2 days) and placebo pills (16.5 \pm 3.4 days) and again completed nicotine and placebo patch scans towards the end of each pill interval (Fig. S1). In other words, participants were scanned twice without drugs (i.e., pre-pill/ placebo-patch and placebo-pill/placebo-patch sessions) and four times after receiving pharmacological interventions (i.e., pre-pill/nicotine-patch, placebo-pill/nicotine-patch, varenicline-pill/nicotine-patch, and varenicline-pill/placebo-patch sessions). Examination of smokers in both the absence and presence of drugs allowed us to assess the state/condition specificity (e.g., only present during withdrawal) of any relations between alexithymia, craving, and rsFC. Varenicline (Chantix ${ }^{\circledR}$, Pfizer) was administered according to standard guidelines and distributed in blister packs identical to sucrose placebo pills. Transdermal nicotine (NicoDerm CQ ${ }^{\circledR}$, GSK) or placebo patches were applied to the back. We used a multiple dosing strategy to match daily nicotine intake, nonsmokers: $7 \mathrm{mg}$ patches; smokers: $21,28,35$, or $42 \mathrm{mg}$ patches (for 10-15, 16-20, 21-25, and >25 cigarettes/day, respectively).

Electronic supplementary material The online version of this article (doi:10.1007/s00213-013-3018-8) contains supplementary material, which is available to authorized users. 
We instructed smokers to have their last cigarette $12 \mathrm{~h}$ before their scheduled arrivals. Upon arrival, all participants were tested for recent drug and alcohol use and for expired carbon monoxide (CO) levels. Given that the half-life of $\mathrm{CO}$ during sleep can be up to 4-8 $\mathrm{h}$ (SRNT Subcommittee 2002), we used a guideline of less than or equal to 15 parts per million (ppm) to verify abstinence. Indicative of compliance, smokers' $\mathrm{CO}$ levels were lower on scan visits $(6.9 \pm 2.6 \mathrm{ppm})$ relative to visits not requiring abstinence $\left(18.6 \pm 8.9 \mathrm{ppm} ; t_{22}=-7.8, p<0.001\right)$; nonsmokers' $C O$ levels did not differ ( $1.9 \pm 0.3$ vs. $1.8 \pm 0.4 \mathrm{ppm} ; t_{18}=1.1, p=0.3$ ).

\section{Self-reports}

We assessed alexithymic traits and state variations in tobacco craving using previously validated and routinely employed self-reports. Participants completed the 20 -item Toronto Alexithymia Scale (TAS-20; Bagby et al. 1994) once during the study and a total score was calculated. Higher scores indicate more alexithymic characteristics (range 20-100). Participants rated on a five point scale how much they agreed or disagreed with statements such as: "It is difficult for me to find the right words for my feelings," "I prefer talking to people about their daily activities rather than their feelings," and "I often don't know why I am angry." As the TAS-20 total score is predictive of poorer drug abuse prognoses (Cleland et al. 2005; Thorberg et al. 2011) and correlates with insula and ACC function (Meriau et al. 2006; Reker et al. 2010), we focused specifically on this total score in our analyses. Alexithymia is best characterized as a dimensional rather than a categorical construct (Chen et al. 2011; Mattila et al. 2010). While the TAS-20 score is a continuous variable, pre-

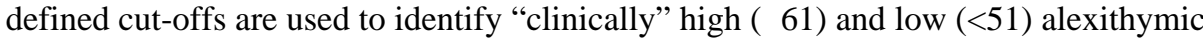
individuals (Taylor 2000). Our participants were not "clinically" alexithymic according to this criterion (range 22-55). We examined individual differences in alexithymic traits across participants free from psychiatric disorders (other than nicotine dependence).

Smokers' tobacco cravings were assessed after each scan sessions with the 12-item Tobacco Craving Questionnaire (TCQ: Heishman et al. 2008) which consists of four factors: emotionality, expectancy, compulsivity, and purposefulness. We examined the link between alexithymia and TCQ total and subscale scores with emphasis on the emotionality factor. The emotionality subscale (range 3-21: higher scores indicate more craving) contains three items: (1) "I would be less irritable now if I could smoke," (2) "If I were smoking now, I could think more clearly," and (3) "I could control things better now if I could smoke." We also assessed mood states in both smokers and nonsmokers using the Positive and Negative Affect Schedule (PANAS: Watson et al. 1988). The TCQ and PANAS were completed $~ 5.5$ $\mathrm{h}$ after patch application and $\sim 2.5 \mathrm{~h}$ after MRI scanning.

\section{rsFC data collection and processing}

We acquired imaging data with a Siemens 3 T Magnetom Allegra scanner. During the 8-min resting scan, participants were instructed to simply relax with eyes closed and remain still. Resting data were collected $\sim 2.5-3 \mathrm{~h}$ after patch application (see SI for data collection parameters). We processed resting data as previously described (Sutherland et al. 2013a). Functional data were slice-time and motion corrected, aligned with anatomical images, and normalized into Talairach space ( $3 \mathrm{~mm}^{3}$ voxels). Images were spatially blurred $(6 \mathrm{~mm}$ kernel) and the time series underwent de-trending and band-pass filtering $(0.01-0.1 \mathrm{~Hz})$. Global fluctuations from non-neuronal physiological processes were reduced by regressing out nuisance signals: i.e., the first three principal components (PCs) derived from the time courses of white matter (WM) voxels and the first three PCs from cerebrospinal fluid (CSF) voxels (Behzadi et al. 2007). Motion-correction parameters also were used to remove signals related to head movement. Furthermore, we employed two additional strategies to reduce motion-related confounds (Sutherland et al. 2013a): (1) the censoring of volumes associated with large movements (Power et al. 2012), and (2) the use of a summary motion metric as a 
confounding variable in group-level analyses (Satterthwaite et al. 2012). For each subject and session, we computed correlation coefficient (CC) images by correlating each voxel's time course with a reference time course from a predefined seed region. Resulting subjectlevel CC images were Fisher's $Z$-transformed ( $Z$-images).

rsFC seeds-When considering insula's functional organization, previous studies have identified three discernible subregions along a ventral-anterior to dorsal-posterior trajectory with distinct rsFC topographies (Cauda et al. 2011; Deen et al. 2011; Taylor et al. 2009). To replicate and extend these findings, we examined the rsFC of right and left insular subregions using seeds (29 voxels; Fig. 1 ) centered on previously defined coordinates in the aI (aI: $x= \pm 34 ; y=14 ; z=-6$, Talairach [mm]), $\mathrm{mI}(\mathrm{mI}: x= \pm 36 ; y=4 ; z=2)$, and $(x= \pm 38 ; y=-10$; $z=6$ ). We then identified and compared intrinsic connectivity networks (ICNs) associated with each insular subregion to confirm that these seeds extracted distinct topographies. Overall rsFC maps were created by averaging each participant's $Z$-images across all six scan sessions and submitting these session-averaged maps to group-level, one-sample $t$-tests. To determine if rsFC differed between aI, mI, and $\mathrm{pI}$, we performed three paired-sample $t$-tests per hemisphere (aI vs. pI, aI vs. $\mathrm{mI}$, $\mathrm{mI}$ vs. $\mathrm{pI}$; $p_{\text {corrected }}<0.001$ : $p_{\text {voxel-wise }}<10^{-6}$; clusterextent: 10 voxels). We used this stringent threshold to control for $a$-inflation associated with multiple comparisons. As aberrant ACC function also has been linked with alexithymia, we examined the rsFC of the right and left dorsal ACC (dACC) using seeds centered on coordinates $(x= \pm 9 ; y=20 ; z=31)$ previously linked with both alexithymia and cigarette cue reactivity/craving (Engelmann et al. 2012; Heinzel et al. 2010).

rsFC analyses-To identify regions whose rsFC with a seed was influenced as a function of alexithymia and/or smoking status, we analyzed session-averaged $Z$-images in a wholebrain linear-mixed effects framework. We focused on session-averaged $Z$-images to relate trait alexithymia with stable "trait-like" rsFC independent of state variations. Subject-level $Z$-images from each seed were entered into separate models including factors for GROUP (smoker vs. nonsmoker), alexithymia (ALEX: TAS-20 score), and confounding variables of no interest (motion and age). In other words, we conducted whole-brain analyses of covariance (ANCOVAs) to identify brain areas whose rsFC with a seed region: (1) differed between smokers versus nonsmokers (GROUP main effect), (2) was predicted by alexithymia regardless of group (ALEX main effect), and/or (3) was differentially predicted by alexithymia in smokers versus nonsmokers (GROUP $\times$ ALEX interaction). We applied a threshold of $p_{\text {corrected }}<0.006$ (Bonferroni: $a=0.05 / 8 ; p_{\text {voxel-wise }}<0.005$; cluster-extent: 64 voxels) to the statistical maps and extracted $Z$-values (i.e., rsFC strength) from identified clusters for further examination.

Mediation analyses-To examine a potential relation between alexithymia and craving, we initially performed correlation analyses between TAS-20 scores and TCQ ratings from smokers' first encounter (of two) with extended smoking deprivation in the absence of drug administration (i.e., session-specific values obtained under "full-withdrawal" during the prepill/placebo-patch session). We then conducted a mediation analysis testing whether the relation between alexithymia $(X)$ and craving $(Y)$ was explained by rsFC strength $(M)$ in circuits identified in the group-level analyses above (model: alexithymia $\rightarrow \mathrm{rsFC} \rightarrow$ craving). By convention, path "c" in this model refers to the total effect of alexithymia on craving, path "a" refers to the impact of alexithymia on rsFC, and path "b" refers to the effect of rsFC on craving (controlling for alexithymia). The mediation analysis decomposed the total effect of alexithymia on craving (path c) into direct (path c') and indirect effects (path ab: i.e., $\mathrm{c}=\mathrm{c}^{\prime}$ $+\mathrm{ab}$ ). rsFC is considered to completely mediate the relation between alexithymia and craving if the coefficients from paths $a, b$, and ab are significant and thus path c' differs from c. Age was included as a confounding variable and data are reported as unstandardized path 
coefficients $(\beta)$ and standard errors $(S E)$. The ab indirect path is considered significant if the asymmetric, bias-corrected $95 \%$ confidence interval (95\% CI), computed via a bootstrapping approach (Preacher and Hayes 2008), does not encompass zero.

To replicate results from smoker's first full-withdrawal session, we conducted another mediation analysis using data from smokers' second "full-withdrawal" session (i.e., placebopill/placebo-patch). Subsequently, additional mediation analyses were performed using data from the remaining four sessions when smokers received varenicline and/or nicotine to evaluate the state/condition specificity of the mediation effect during withdrawal. In statistical terms, such state specificity is indicated by a moderated mediation effect. A moderated mediation occurs when the effect of the independent variable $(X$ : alexithymia) on the dependent variable $(Y$ : craving) through a mediator variable $(M:$ rsFC) differs depending on the level of a moderator variable ( $W$ : full-withdrawal vs. drug administration). A significant $M \times W$ interaction indicates that the indirect effect of $X$ on $Y$ through $M$ varies across levels of $W$ (Fig. S4). We determined the significance of the conditional indirect effect $(M \times W$ interaction) using the framework of Preacher and colleagues (2007). In sum, we examined whether the alexithymia $\rightarrow \mathrm{rsFC} \rightarrow$ craving relation differed between the first full-withdrawal session versus the session when varenicline and nicotine were coadministered.

\section{Results}

\section{Insular subregions showed distinct rsFC topographies}

Using the six seeds (right/left aI, mI, and pI), we identified overlapping yet distinct ICNs associated with insular sub-regions (Fig. S2). Specifically, when considering all participants and sessions: (1) the aI demonstrated greater $\mathrm{rsFC}$ strength with pregenual/rostral ACC relative to either the $\mathrm{mI}$ or $\mathrm{pI},(2)$ the $\mathrm{mI}$ was more strongly interconnected with dorsal ACC and adjacent pre-supplemental motor area in comparison to the other two insular seeds, and (3) the $\mathrm{pI}$ showed greatest rsFC with mid-cingulate, supplemental motor area, and sensorimotor regions (Fig. 2). These results confirm that our preselected seeds extracted distinct topographies. Additionally, bilateral dACC seeds identified expected ICNs anchored by bilateral insula and posterior medial prefrontal regions (Fig. S3).

\section{Alexithymia differentially predicted rsFC in smokers versus nonsmokers}

We next performed separate whole-brain ANCOVAs to identify brain regions whose rsFC with these eight seeds was influenced as a function of smoking status (GROUP) and/or alexithymia (ALEX). TAS-20 scores differentially predicted session-averaged rsFC strength between right aI and vmPFC in smokers versus nonsmokers as indicated by a whole-brain GROUP x ALEX interaction (Fig. 3a). Specifically, higher TAS-20 scores predicted decreased rsFC in this right aI-vmPFC circuit in smokers but not in nonsmokers. No significant clusters were detected when considering either the whole-brain GROUP or ALEX main effects. Suggesting the regional specificity of alexithymia's impact on this aIvmPFC circuit, no effects were detected when considering the homologous left aI seed, nor the left $\mathrm{mI}$, left $\mathrm{pI}$, or right $\mathrm{pI}$ seeds. Alexithymia differentially predicted rsFC strength between right $\mathrm{mI}$ and superior temporal gyrus (STG) in smokers versus nonsmokers in a fashion similar to that described above for the aI-vmPFC circuit (Table S2).

We also investigated the relation between TAS-20 scores and left/right dACC rsFC. Focusing on the left seed, alexithymia differentially predicted rsFC strength in a dACCinsula circuit in smokers versus nonsmokers (Fig. 3b). Similar GROUP $\times$ ALEX interactions were also detected when considering the right dACC's rsFC with bilateral STG, bilateral 
inferior parietal lobule, left middle frontal gyrus, and right middle occipital gyrus (Table S2).

\section{Alexithymia predicted craving during withdrawal}

We performed correlation analyses on TAS-20 and TCQ scores from smokers' first fullwithdrawal session. Focusing on the TCQ emotionality scale, higher TAS-20 scores predicted elevated craving during withdrawal $(r=0.45, p=0.03$; Fig. $4 \mathrm{a})$. No relations were detected between TAS-20 and TCQ total or other subscale scores $(p>0.2)$.

\section{al-vmPFC circuitry mediated alexithymia's influence on craving}

As alexithymia correlated with both aI-vmPFC rsFC and TCQ emotionality ratings, we subsequently conducted a mediation analysis testing the hypothesis that the effect of trait alexithymia $(X)$ on state craving $(Y)$ was mediated by session-specific rsFC strength in the right aI-vmPFC circuit $(M)$. As shown in Fig. 4b, the aI-vmPFC circuit fully mediated the alexithymia-craving relation during smoker's first full-withdrawal session. Specifically, when including the aI-vmPFC mediator in the model, alexithymia's direct effect on craving failed to reach significance (c' path: $\beta=0.2, S E=0.2, p=0.3$ ), whereas the indirect effect was significant (ab path: $95 \% \mathrm{CI}=0.02-0.46$ ). These outcomes indicate that higher TAS-20 scores predicted reduced aI-vmPFC circuit strength and, in turn, reduced aI-vmPFC circuit strength predicted increased craving during withdrawal.

This mediation effect was internally replicated when considering smokers' second fullwithdrawal sessions (95\% CI=0.1-0.9) but critically, not any of the other four sessions following varenicline and/or nicotine administration (Table S3). To statistically support the notion that the aI-vmPFC circuit mediated alexithymia's impact on craving only during withdrawal, we conducted a moderated mediation analysis comparing the alexithymia $\rightarrow \mathrm{aI}-$ $\mathrm{vmPFC} \rightarrow$ craving relation from the first full-withdrawal session versus the session when varenicline and nicotine were co-administered. We detected a significant moderate mediation effect indicating that the relation between alexithymia and craving was mediated by aI-vmPFC rsFC during withdrawal but not following drug administration $(M \times W$ interaction: $\beta=21.1, S E=9.9, p=0.04$; Fig. S4). This outcome provides evidence for the state/ condition specificity of the aI-vmPFC mediational effect.

No relations between craving and rsFC in the right mI-STG (Table S2) or dACC-insula circuits (Fig. 3b) were detected $(p>0.2)$. Because such a relation is a prerequisite for a mediation, these outcomes provide evidence for the circuit specificity of the aI-vmPFC mediation effect. Given that these circuits appeared unrelated to craving, they are not discussed further.

\section{al-vmPFC circuitry did not mediate alexithymia's influence on mood}

To relate trait alexithymia with state self-reports from non-smokers, we performed correlation analyses between TAS-20 scores and PANAS ratings from the pre-pill/placebopatch session. In nonsmokers, higher TAS-20 scores predicted lower PANAS positive ( $r=$ $-0.62, p=0.005)$, but not negative affect $(r=0.15, p=0.5$; AFFECT $\times$ ALEX interaction: $\left.F_{1,17}=10.3, p=0.005\right)$. However, this alexithymia-mood relation was not mediated by the aIvmPFC circuit described above (Fig. S5). These outcomes provide evidence for the domain/ construct specificity of the aI-vmPFC mediational effect. In smokers, no relation between TAS-20 and positive or negative affect were detected $\left(p^{\prime} s>0.2\right)$. 


\section{Discussion}

Alexithymia is a stable personality trait associated with reduced emotional insight and structural/functional alterations in the insula and ACC (Swart et al. 2009; Wingbermuhle et al. 2012). Despite accumulating evidence indicative of a link between alexithymia and drug use (Bruce et al. 2012; Kun and Demetrovics 2010; Saladin et al. 2012), little research has investigated the neurobiological mechanisms contributing to this relation. In this secondary analysis of data from a larger study, we used rsFC to investigate the interrelations between alexithymia, tobacco craving, and the insula's circuit-level interactions with other brain regions. We identified a ventral-anterior to dorsal-posterior trajectory in the insula's functional organization and more importantly, observed that higher alexithymia in smokers predicted weaker rsFC between the right aI and vmPFC. Confirming the clinical relevance of this personality trait, we also observed that higher alexithymia predicted more severe tobacco craving during withdrawal. Critically, the aI-vmPFC circuit fully mediated this alexithymia-craving relation as higher TAS-20 scores forecasted a weaker circuit, and in turn, a weaker circuit conferred increased liability for craving. These results suggest that individual differences in alexithymic characteristics and/or aI-vmPFC rsFC may be relevant factors for smoking cessation success.

Our results support the tri-parcellation of insular organization along a ventral-anterior to dorsal-posterior gradient using rsFC (Cauda et al. 2011; Deen et al. 2011; Taylor et al. 2009). Such a parcellation is consistent with previous fractionations of the insula synthesized from functional, anatomical, physiological, and clinical data (Craig 2010; Kurth et al. 2010; Nieuwenhuys 2012). We observed that the $\mathrm{pI}$ was strongly interconnected with constituents of a commonly observed intrinsic sensorimotor network (Biswal et al. 1995) consistent with the pI's role in somatosensation and primary interoception (Craig 2002). The $\mathrm{mI}$ showed greatest coupling with the dorsal "cognitive division" of ACC (Bush et al. 2000) consistent with the mI's role in the initiation, maintenance, and adjustment of attentional resources (Dosenbach et al. 2006). Finally, the aI was strongly interconnected with the pregenual/rostral "emotional division" of ACC (Bush et al. 2000) consistent with the al's role in the processing, generation, and awareness of affective states (Craig 2010; Kurth et al. 2010). A posterior-to-anterior integration of interoceptive information with cognitive and affective processing streams culminating in the aI has been conceptualized as the neurobiological instantiation of subjective emotional experience and awareness (Craig 2009, 2010) with an emphasis on the right aI regarding arousing or aversive states (Craig 2005; Critchley et al. 2004).

In light of the right al's involvement with the processing of aversive emotional states, it is particularly notable that alexithymia differentially predicted rsFC between smokers versus nonsmokers in a specific right (but not left) insula circuit. Our observation that alexithymia predicted decreased aI-vmPFC circuit strength in smokers but not nonsmokers may be related to structural alterations in these regions associated with an extended smoking history. For example, increased gray matter density in the aI (Zhang et al. 2011) and decreased cortical thickness in the vmPFC (Kuhn et al. 2010) has been detected in smokers relative to nonsmokers. Such structural alterations corroborate functional/clinical observations implicating these same regions in the perpetuation of smoking behaviors (Franklin et al. 2011; Kober et al. 2010; Naqvi et al. 2007).

Specifically, theoretical accounts suggest that circuit-level interactions between the insula and vmPFC are associated with cognitive and affective processes at multiple stages of the addiction cycle (Naqvi and Bechara 2010). Altered insular function may underlie impaired insight, compromised self-awareness, and/or altered interoceptive abilities which have been conceptualized as critical factors underlying drug addiction (Goldstein et al. 2009; Kun and 
Demetrovics 2010; Verdejo-Garcia et al. 2012). Furthermore, the vmPFC has been regarded as a critical hub in the neurocircuitry of affect regulation (cf., Kim et al. 2011; Myers-Schulz and Koenigs 2012). Neuroimaging evidence indicates that labeling negative emotional stimuli ("putting feelings into words") results in increased activation of the vmPFC and, in turn, this increased vmPFC activity is thought to alleviate aversive emotional states via suppression of amygdala functioning (Foland-Ross et al. 2010; Lieberman et al. 2007). In chronic smokers deprived of nicotine, elevated amygdala activity covaries with increased smoking urges (Wang et al. 2007) and cigarette smoking dampens amygdala hyperactivity (Zubieta et al. 2005). Elevated insula, vmPFC, and amygdala responses to smoking-related cues have been associated with increased craving (Chase et al. 2011; Engelmann et al. 2012) and greater relapse susceptibility (Janes et al. 2010). A weakened right aI-vmPFC circuit may contribute to emotion dysregulation and drug craving particularly emergent during withdrawal.

Indeed, linking this weakened circuit with a clinically relevant outcome, we observed that right aI-vmPFC connectivity strength completely mediated the relation between alexithymia and craving during withdrawal. Converging evidence from multiple drugs of abuse connects elevated alexithymia with poorer prognoses (Speranza et al. 2004) including: reduced emotion regulation and treatment engagement in substance abusers (Cleland et al. 2005; Stasiewicz et al. 2012), greater dependence, use severity, and craving in alcoholics (Thorberg et al. 2009, 2011), and elevated aggression and craving in methamphetamine addicts (Payer et al. 2012; Saladin et al. 2012). Additionally, alexithymia has been reported to correlate with subcortical, temporal, and frontal brain activations during stress-guided imagery in cocaine addicts ( $\mathrm{Li}$ and Sinha 2006) and increased aI gray matter density in smokers (Zhang et al. 2011). Our results confirm and extend these previous findings by relating higher alexithymia not only with more severe tobacco craving but also with reduced functional connectivity in a precise brain circuit. Specifically, if a smoker had a "weaker" circuit, that smoker was more likely to experience higher degrees of craving during withdrawal. Conversely, if a smoker had a "stronger" aI-vmPFC circuit, that smoker was less likely to experience higher degrees of craving during withdrawal. One possible interpretation is that a stronger aI-vmPFC circuit is "protective" against craving during smoking abstinence.

The TAS-20 describes a person's level of difficulty identifying and describing emotions as well as their propensity to understand themselves as responding to outside influences rather than having an internal locus of control. Decreased abilities to perceive, evaluate, and communicate emotions may result in poorer emotion regulation and the persistence of aversive emotional states (Chen et al. 2011; Pollatos and Gramann 2012; Swart et al. 2009). Such deficits in the cognitive processing and regulation of emotions may contribute to the onset, exacerbation, and/or maintenance of drug use via negative reinforcement mechanisms (Baker et al. 2004; Cheetham et al. 2010; Kun and Demetrovics 2010). We speculate that someone who has difficulty processing affective information beyond recognizing an aversive feeling and who experiences relief via a cigarette may be drawn to smoking. Furthermore, the onset of a negative emotion (e.g., angry, sad, anxious) in an established smoker with higher degrees of alexithymia may be evaluated simply as "I need a cigarette." In turn, relief may be obtained by smoking.

We conducted multiple supplemental analyses to more fully characterize the aI-vmPFC circuit and its associated behavioral consequences. First, we internally replicated the mediating role of the aI-vmPFC circuit in an alexithymia-craving relation during withdrawal by assessing smokers during two separate "full-withdrawal" sessions. Second, we provided evidence for the state/conditional specificity of the aI-vmPFC mediational effect by examining smokers following pharmacological interventions. A moderated 
mediation analysis indicated that the aI-vmPFC circuit mediated the alexithymia-craving relationship during withdrawal but not following drug administration. This outcome indicates that the behavioral consequences of a weakened aI-vmPFC circuit only manifested during the withdrawn state. Finally, we provided evidence for the domain/construct specificity of the aI-vmPFC circuit by demonstrating that the circuit was unrelated to an alexithymia-mood relation observed in nonsmokers. The nonsmoker-mood results can also be viewed as a "negative control." In other words, a significant correlation between alexithymia and a self-report measure was not sufficient to yield the aI-vmPFC mediational effect.

Our results regarding aI-vmPFC circuit-level interactions may also be considered in light of studies assessing the subjective value of rewards and decision making processes.

Neuroimaging investigations have provided evidence that the vmPFC encodes the subjective value of rewards and actions (Hare et al. 2009; Kable and Glimcher 2009). In addition to alterations in insula and vmPFC functioning (Wingbermuhle et al. 2012), alexithymia has also been associated with reduced hedonic capacity (cf., Loas et al. 1997a; Prince and Berenbaum 1993), reduced sensitivity to negative outcomes (Bibby and Ferguson 2011), and compromised performance in the Iowa Gambling Task (Ferguson et al. 2009; Kano et al. 2011). As the integration of interoceptive information (insula) with subjective value information (vmPFC) is critical for optimal decision making (Bechara and Damasio 2005), we speculate that reduced aI-vmPFC functional coupling may contribute to alterations in reward/punishment processing associated with alexithymia and/or nicotine addiction.

A weakened aI-vmPFC circuit appears to render smokers with high alexithymic tendencies particularly vulnerable to tobacco craving. As tobacco craving perpetuates smoking and precipitates relapse (Baker et al. 2012; Shiffman et al. 1997), our results suggest that individual differences in alexithymia may be a relevant factor for cessation success. We suggest that smokers higher in alexithymia may benefit from the acquisition of skills associated with the perception, processing, and regulation of emotions in the service of craving mitigation. Also, pharmacological agents such as venlafaxine, a serotonin and norepinephrine reuptake inhibitor, appear to augment emotional awareness (Cravello et al. 2009) and have been proposed as adjunct interventions for alcoholics with higher alexithymia (Thorberg et al. 2011). As venlafaxine improves cessation rates in some subgroups of smokers (Cinciripini et al. 2005), we speculate that smokers higher in alexithymia may be those most likely to benefit from such a pharmacological intervention. Strengthening the functional interaction between the right aI and vmPFC via behavioral therapies, pharmacological agents, or transcanial magnetic stimulation to the insula may promote smoking abstinence.

Our findings should be considered in light of remaining issues. First, while the TAS-20 has been psychometrically validated and is commonly used to explore relations between alexithymia, brain function, and drug abuse (Cleland et al. 2005; Thorberg et al. 2009; Wingbermuhle et al. 2012), it is a self-report instrument designed to probe impaired introspective abilities. Thus, an impaired ability to introspect may lead to inaccuracies in participant evaluations. Second, the range of TAS-20 scores from our participants (i.e., 2255) was rather limited relative to the full dynamic range of the instrument (i.e., 20-100) as well as that seen in other neuroimaging studies employing extreme-group analytical strategies (e.g., Kano et al. 2003). Third, further research is necessary to clarify the potential laterality of insular function with respect to nicotine addiction. Previously, we observed that elevated left insula-vmPFC rsFC was associated with increased withdrawal severity and was reduced by varenicline and nicotine administration (Sutherland et al. 2013a), suggesting a "susceptibility circuit" contributing to the perpetuation of smoking. Here, elevated right insula-vmPFC rsFC was associated with reduced tobacco craving suggesting a "protective 
circuit" that may contribute to cessation success. The literature on insular laterality in nicotine addiction remains disparate. For example, although smoking disruption was noted following strokes affecting either the right or left insula, the effect appeared more robust for right-lateralized lesions (Naqvi et al. 2007). On the other hand, greater left insula gray matter density has been reported in smokers versus nonsmokers (Zhang et al. 2011). Finally, while preliminary evidence suggests higher alexithymia is related to quicker relapse (Loas et al. 1997b; Ziolkowski et al. 1995), the ability of alexithymia or aI-vmPFC circuit strength to predict cessation outcomes remains indeterminate.

Our results underscore the utility of examining functional connectivity to gain deeper insight into the altered neurocircuitry of addiction (Sutherland et al. 2013c). We triangulated the relationship between a stable personality trait previously associated with poorer drug abuse prognoses, state variability in a clinically relevant craving measure, and the functional connectivity strength of a precise brain circuit. Specifically, using a hypothesized insula seed and a whole-brain search strategy, we uncovered a right aI-vmPFC circuit associated with alexithymia whose weakened functional connectivity was found to confer increased liability for tobacco craving during smoking abstinence. Individual differences in alexithymia and/or aI-vmPFC functional connectivity strength may be relevant factors for smoking cessation success.

\section{Acknowledgments}

This work was sponsored by the National Institute on Drug Abuse Intramural Research Program, National Institutes of Health, Department of Health and Human Services (NIDA-IRP/NIH/DHHS). We thank Eliscia Smith, Angela Neal, Kimberly Slater, Loretta Spurgeon, Anita Signau and the NIDA-IRP nurses, pharmacy, and recruitment staff for assistance with data collection.

\section{References}

Bagby RM, Parker JDA, Taylor GJ. The 20-item Toronto-Alexithymia-Scale: 1. Item selection and cross-validation of the factor structure. J Psychosom Res. 1994; 38:23-32. [PubMed: 8126686]

Baker TB, Piper ME, McCarthy DE, Majeskie MR, Fiore MC. Addiction motivation reformulated: an affective processing model of negative reinforcement. Psychol Rev. 2004; 111:33-51. [PubMed: 14756584]

Baker TB, Piper ME, Schlam TR, Cook JW, Smith SS, Loh WY, Bolt D. Are tobacco dependence and withdrawal related amongst heavy smokers? relevance to conceptualizations of dependence. J Abnorm Psychol. 2012; 121(4):909-921. [PubMed: 22642839]

Baughman HM, Schwartz S, Schermer JA, Veselka L, Petrides KV, Vernon PA. A Behavioral-genetic study of alexithymia and its relationships with trait emotional intelligence. Twin Res Hum Genet. 2011; 14:539-543. [PubMed: 22506309]

Bechara A, Damasio AR. The somatic marker hypothesis: a neural theory of economic decision. Games Econ Behav. 2005; 52:336-372.

Behzadi Y, Restom K, Liau J, Liu TT. A component based noise correction method (CompCor) for BOLD and perfusion based fMRI. Neuroimage. 2007; 37:90-101. [PubMed: 17560126]

Bibby PA, Ferguson E. The ability to process emotional information predicts loss aversion. Personal Individ Differ. 2011; 51:263-266.

Biswal B, Yetkin FZ, Haughton VM, Hyde JS. Functional connectivity in the motor cortex of resting human brain using echo-planar MRI. Mag Reson Med. 1995; 34:537-541.

Borsci G, Boccardi M, Rossi R, Rossi G, Perez J, Bonetti M, Frisoni GB. Alexithymia in healthy women: a brain morphology study. J Affect Disord. 2009; 114:208-215. [PubMed: 18718670]

Bruce G, Curren C, Williams L. Alexithymia and alcohol consumption: the mediating effects of drinking motives. Addict Behav. 2012; 37:350-352. [PubMed: 22154505]

Bush G, Luu P, Posner MI. Cognitive and emotional influences in anterior cingulate cortex. Trends Cogn Sci. 2000; 4:215-222. [PubMed: 10827444] 
Cauda F, D'Agata F, Sacco K, Duca S, Geminiani G, Vercelli A. Functional connectivity of the insula in the resting brain. Neuroimage. 2011; 55:8-23. [PubMed: 21111053]

Chase HW, Eickhoff SB, Laird AR, Hogarth L. The neural basis of drug stimulus processing and craving: an activation likelihood estimation meta-analysis. Biol Psychiatry. 2011; 70:785-793. [PubMed: 21757184]

Cheetham A, Allen NB, Yucel M, Lubman DI. The role of affective dysregulation in drug addiction. Clin Psychol Rev. 2010; 30:621-634. [PubMed: 20546986]

Chen J, Xu T, Jing J, Chan RC. Alexithymia and emotional regulation: a cluster analytical approach. BMC Psychiatry. 2011; 11:33. [PubMed: 21345180]

Cinciripini PM, Tsoh JY, Wetter DW, Lam C, de Moor C, Cinciripini L, Baile W, Anderson C, Minna JD. Combined effects of venlafaxine, nicotine replacement, and brief counseling on smoking cessation. Exp Clin Psychopharmacol. 2005; 13:282-292. [PubMed: 16366758]

Cleland C, Magura S, Foote J, Rosenblum A, Kosanke N. Psychometric properties of the Toronto Alexithymia Scale (TAS-20) for substance users. J Psychosom Res. 2005; 58:299-306. [PubMed: 15865955]

Craig AD. How do you feel? Interoception: the sense of the physiological condition of the body. Nat Rev Neurosci. 2002; 3:655-666. [PubMed: 12154366]

Craig AD. Forebrain emotional asymmetry: a neuroanatomical basis? Trends Cogn Sci. 2005; 9:566571. [PubMed: 16275155]

Craig AD. How do you feel - now? The anterior insula and human awareness. Nature Rev Neurosci. 2009; 10:59-70. [PubMed: 19096369]

Craig AD. The sentient self. Brain Struct Funct. 2010; 214:563-577. [PubMed: 20512381]

Cravello L, Caltagirone C, Spalletta G. The SNRI venlafaxine improves emotional unawareness in patients with post-stroke depression. Hum Psychopharmacol Clin Exp. 2009; 24:331-336.

Critchley HD, Wiens S, Rotshtein P, Ohman A, Dolan RJ. Neural systems supporting interoceptive awareness. Nature Neurosci. 2004; 7:189-195. [PubMed: 14730305]

de Timary P, Luts A, Hers D, Luminet O. Absolute and relative stability of alexithymia in alcoholic inpatients undergoing alcohol withdrawal: relationship to depression and anxiety. Psychiatry Res. 2008; 157:105-113. [PubMed: 17884180]

Deen B, Pitskel NB, Pelphrey KA. Three systems of insular functional connectivity identified with cluster analysis. Cereb Cortex. 2011; 21:1498-1506. [PubMed: 21097516]

Dosenbach NUF, Visscher KM, Palmer ED, Miezin FM, Wenger KK, Kang HSC, Burgund ED, Grimes AL, Schlaggar BL, Petersen SE. A core system for the implementation of task sets. Neuron. 2006; 50:799-812. [PubMed: 16731517]

Engelmann JM, Versace F, Robinson JD, Minnix JA, Lam CY, Cui Y, Brown VL, Cinciripini PM. Neural substrates of smoking cue reactivity: a meta-analysis of fMRI studies. Neuroimage. 2012; 60:252-262. [PubMed: 22206965]

Ferguson E, Bibby PA, Rosamond S, O'Grady C, Parcell A, Amos C, McCutcheon C, O'Carroll R. Alexithymia, cumulative feedback, and differential response patterns on the Iowa Gambling Task. J Personal. 2009; 77:883-902.

Ferguson SG, Shiffman S. The relevance and treatment of cue-induced cravings in tobacco dependence. J Subst Abus Treat. 2009; 36:235-243.

Foland-Ross LC, Altshuler LL, Bookheimer SY, Lieberman MD, Townsend J, Penfold C, Moody T, Ahlf K, Shen JK, Madsen SK, Rasser PE, Toga AW, Thompson PM. Amygdala reactivity in healthy adults is correlated with prefrontal cortical thickness. J Neurosci. 2010; 30:16673-16678. [PubMed: 21148006]

Fox MD, Raichle ME. Spontaneous fluctuations in brain activity observed with functional magnetic resonance imaging. Nat Rev Neurosci. 2007; 8:700-711. [PubMed: 17704812]

Franklin T, Wang Z, Suh JJ, Hazan R, Cruz J, Li Y, Goldman M, Detre JA, O'Brien CP, Childress AR. Effects of varenicline on smoking cue-triggered neural and craving responses. Arch Gen Psychiat. 2011; 68:516-526. [PubMed: 21199958]

Frewen PA, Lanius RA, Dozois DJA, Neufeld RWJ, Pain C, Hopper JW, Densmore M, Stevens TK. Clinical and neural correlates of alexithymia in posttraumatic stress disorder. J Abnorm Psychol. 2008; 117:171-181. [PubMed: 18266495] 
Goldstein RZ, Craig AD, Bechara A, Garavan H, Childress AR, Paulus MP, Volkow ND. The neurocircuitry of impaired insight in drug addiction. Trends Cogn Sci. 2009; 13:372-380. [PubMed: 19716751]

Greicius MD, Supekar K, Menon V, Dougherty RF. Resting-state functional connectivity reflects structural connectivity in the default mode network. Cereb Cortex. 2009; 19:72-78. [PubMed: 18403396]

Hare TA, Camerer CF, Rangel A. Self-control in decision-making involves modulation of the vmPFC valuation system. Science. 2009; 324:646-648. [PubMed: 19407204]

Heinzel A, Schafer R, Muller HW, Schieffer A, Ingenhag A, Northoff G, Franz M, Hautzel H. Differential modulation of valence and arousal in high-alexithymic and low-alexithymic individuals. Neuroreport. 2010; 21:998-1002. [PubMed: 20811301]

Heishman SJ, Singleton EG, Pickworth WB. Reliability and validity of a short form of the tobacco craving questionnaire. Nicotine Tob Res. 2008; 10:643-651. [PubMed: 18418787]

Herbert BM, Herbert C, Pollatos O. On the relationship between interoceptive awareness and alexithymia: is interoceptive awareness related to emotional awareness? J Personal. 2011; 79:1149-1175.

Hong LE, Gu H, Yang Y, Ross TJ, Salmeron BJ, Buchholz B, Thaker GK, Stein EA. Association of nicotine addiction and nicotine's actions with separate cingulate cortex functional circuits. Arch Gen Psychiatry. 2009; 66:431-441. [PubMed: 19349313]

Janes AC, Pizzagalli DA, Richardt S, Frederick BD, Chuzi S, Pachas G, Culhane MA, Holmes AJ, Fava M, Evins AE, Kaufman MJ. Brain reactivity to smoking cues prior to smoking cessation predicts ability to maintain tobacco abstinence. Biol Psychiatry. 2010; 67:722-729. [PubMed: 20172508]

Junghanns K, Tietz U, Dibbelt L, Kuether M, Jurth R, Ehrenthal D, Blank S, Backhaus J. Attenuated salivary cortisol secretion under cue exposure is associated with early relapse. Alcohol Alcohol. 2005; 40:80-85. [PubMed: 15550447]

Kable JW, Glimcher PW. The neurobiology of decision: consensus and controversy. Neuron. 2009; 63:733-745. [PubMed: 19778504]

Kano M, Fukudo S, Gyoba J, Kamachi M, Tagawa M, Mochizuki H, Itoh M, Hongo M, Yanai K. Specific brain processing of facial expressions in people with alexithymia: an (H2O)-O-15-PET study. Brain. 2003; 126:1474-1484. [PubMed: 12764066]

Kano M, Hamaguchi T, Itoh M, Yanai K, Fukudo S. Correlation between alexithymia and hypersensitivity to visceral stimulation in human. Pain. 2007; 132:252-263. [PubMed: 17360119]

Kano M, Ito M, Fukudo S. Neural substrates of decision making as measured with the Iowa Gambling Task in men with alexithymia. Psychosom Med. 2011; 73:588-597. [PubMed: 21862828]

Kano M, Mizuno T, Kawano Y, Aoki M, Kanazawa M, Fukudo S. Serotonin transporter gene promoter polymorphism and alexithymia. Neuropsychobiology. 2012; 65:76-82. [PubMed: 22222552]

Keller DS, Carroll KM, Nich C, Rounsaville BJ. Alexithymia in cocaine abusers - response to psychotherapy and pharmacotherapy. Am J Addict. 1995; 4:234-244.

Kim MJ, Loucks RA, Palmer AL, Brown AC, Solomon KM, Marchante AN, Whalen PJ. The structural and functional connectivity of the amygdala: from normal emotion to pathological anxiety. Behav Brain Res. 2011; 223:403-410. [PubMed: 21536077]

Kober H, Mende-Siedlecki P, Kross EF, Weber J, Mischel W, Hart CL, Ochsner KN. Prefrontalstriatal pathway underlies cognitive regulation of craving. Proc Natl Acad Sci U S A. 2010; 107:14811-14816. [PubMed: 20679212]

Kuhn S, Schubert F, Gallinat J. Reduced thickness of medial orbitofrontal cortex in smokers. Biol Psychiatry. 2010; 68:1061-1065. [PubMed: 20875635]

Kun B, Demetrovics Z. Emotional intelligence and addictions: a systematic review. Subst Use Misuse. 2010; 45:1131-1160. [PubMed: 20441455]

Kurth F, Zilles K, Fox PT, Laird AR, Eickhoff SB. A link between the systems: functional differentiation and integration within the human insula revealed by meta-analysis. Brain Struct Funct. 2010; 214:519-534. [PubMed: 20512376] 
Li CSR, Sinha R. Alexithymia and stress-induced brain activation in cocaine-dependent men and women. J Psychiatry Neurosci. 2006; 31:115-121. [PubMed: 16575427]

Lieberman MD, Eisenberger NI, Crockett MJ, Tom SM, Pfeifer JH, Way BM. Putting feelings into words - affect labeling disrupts amygdala activity in response to affective stimuli. Psychol Sci. 2007; 18:421-428. [PubMed: 17576282]

Loas G, Fremaux D, Boyer P. Anhedonia and alexithymia: distinct or overlapping constructs. Percept Mot Skills. 1997a; 84:415-425. [PubMed: 9106828]

Loas G, Fremaux D, Otmani O, Lecercle C, Delahousse J. Is alexithymia a negative factor for maintaining abstinence? A follow-up study. Compr Psychiatry. 1997b; 38:296-299. [PubMed: 9298323]

Mattila AK, Keefer KV, Taylor GJ, Joukamaa M, Jula A, Parker JDA, Bagby RM. Taxometric analysis of alexithymia in a general population sample from Finland. Pers Individ Differ. 2010; 49:216-221.

Meriau K, Wartenburger I, Kazzer P, Prehn K, Lammers CH, van der Meer E, Villringer A, Heekeren HR. A neural network reflecting individual differences in cognitive processing of emotions during perceptual decision making. Neuroimage. 2006; 33:1016-1027. [PubMed: 16973382]

Miyake Y, Okamoto Y, Onoda K, Shirao N, Okamoto Y, Yamawaki S. Brain activation during the perception of stressful word stimuli concerning interpersonal relationships in anorexia nervosa patients with high degrees of alexithymia in an fMRI paradigm. Psychiatry Res-Neuroimaging. 2012; 201:113-119.

Moriguchi Y, Decety J, Ohnishi T, Maeda M, Mori T, Nemoto K, Matsuda H, Komaki G. Empathy and judging other's pain: an fMRI study of alexithymia. Cereb Cortex. 2007; 17:2223-2234. [PubMed: 17150987]

Myers-Schulz B, Koenigs M. Functional anatomy of ventromedial prefrontal cortex: implications for mood and anxiety disorders. Mol Psychiatry. 2012; 17:132-141. [PubMed: 21788943]

Naqvi NH, Bechara A. The insula and drug addiction: an interoceptive view of pleasure, urges, and decision-making. Brain Struct Funct. 2010; 214:435-450. [PubMed: 20512364]

Naqvi NH, Rudrauf D, Damasio H, Bechara A. Damage to the insula disrupts addiction to cigarette smoking. Science. 2007; 315:531-534. [PubMed: 17255515]

Nieuwenhuys R. The insular cortex: a review. Prog Brain Res. 2012; 195:123-163. [PubMed: 22230626]

Ochsner KN, Gross JJ. The cognitive control of emotion. Trends Cogn Sci. 2005; 9:242-249. [PubMed: 15866151]

Ogrodniczuk JS, Piper WE, Joyce AS. Effect of alexithymia on the process and outcome of psychotherapy: a programmatic review. Psychiatry Res. 2011; 190:43-48. [PubMed: 20471096]

Paradiso S, Vaidya JG, McCormick LM, Jones A, Robinson RG. Aging and alexithymia: association with reduced right rostral cingulate volume. Am J Geriatr Psychiatry. 2008; 16:760-769. [PubMed: 18697882]

Parker JD, Keefer KV, Taylor GJ, Bagby RM. Latent structure of the alexithymia construct: a taxometric investigation. Psychol Assess. 2008; 20:385-396. [PubMed: 19086762]

Payer DE, Lieberman MD, London ED. Neural correlates of affect processing and aggression in methamphetamine dependence. Arch Gen Psychiatry. 2012; 68:271-282. [PubMed: 21041607]

Pollatos O, Gramann K. Attenuated modulation of brain activity accompanies emotion regulation deficits in alexithymia. Psychophysiology. 2012; 49:651-658. [PubMed: 22335425]

Pouga L, Berthoz S, de Gelder B, Grezes J. Individual differences in socioaffective skills influence the neural bases of fear processing: the case of alexithymia. Hum Brain Mapp. 2010; 31:1469-1481. [PubMed: 20127873]

Power JD, Barnes KA, Snyder AZ, Schlaggar BL, Petersen SE. Spurious but systematic correlations in functional connectivity MRI networks arise from subject motion. Neuroimage. 2012; 59:21422154. [PubMed: 22019881]

Preacher KJ, Hayes AF. Asymptotic and resampling strategies for assessing and comparing indirect effects in multiple mediator models. Behav Res Methods. 2008; 40:879-891. [PubMed: 18697684]

Preacher KJ, Rucker DD, Hayes AF. Addressing moderated mediation hypotheses: theory, methods, and prescriptions. Multivar Behav Res. 2007; 42:185-227. 
Prince JD, Berenbaum H. Alexithymia and hedonic capacity. J Res Pers. 1993; 27:15-22.

Reker M, Ohrmann P, Rauch AV, Kugel H, Bauer J, Dannlowski U, Arolt V, Heindel W, Suslow T. Individual differences in alexithymia and brain response to masked emotion faces. Cortex. 2010; 46:658-667. [PubMed: 19524887]

Saladin ME, Santa Ana EJ, LaRowe SD, Simpson AN, Tolliver BK, Price KL, McRae-Clark AL, Brady KT. Does alexithymia explain variation in cue-elicited craving reported by methamphetamine-dependent individuals? Am J Addict. 2012; 21:130-135. [PubMed: 22332856]

Satterthwaite TD, Wolf DH, Loughead J, Ruparel K, Elliott MA, Hakonarson H, Gur RC, Gur RE. Impact of in-scanner head motion on multiple measures of functional connectivity: relevance for studies of neurodevelopment in youth. Neuroimage. 2012; 60:623-632. [PubMed: 22233733]

Shiffman S, Engberg JB, Paty JA, Perz WG, Gnys M, Kassel JD, Hickcox M. A Day at a time: predicting smoking lapse from daily urge. J Abnorm Psychol. 1997; 106:104-116. [PubMed: 9103722]

Silani G, Bird G, Brindley R, Singer T, Frith C, Frith U. Levels of emotional awareness and autism: an fMRI study. Soc Neurosci. 2008; 3:97-112. [PubMed: 18633852]

Speranza M, Corcos M, Stephan P, Loas G, Perez-Diaz F, Lang F, Venisse JL, Bizouard P, Flament M, Halfon O, Jeammet P. Alexithymia, depressive experiences, and dependency in addictive disorders. Subst Use Misuse. 2004; 39:551-579. [PubMed: 15115213]

Subcommittee SRNT. Biochemical verification of tobacco use and cessation. Nic Tob Res. 2002; 4:149-159.

Stasiewicz PR, Bradizza CM, Gudleski GD, Coffey SF, Schlauch RC, Bailey ST, Bole CW, Gulliver $\mathrm{SB}$. The relationship of alexithymia to emotional dysregulation within an alcohol dependent treatment sample. Addict Behav. 2012; 37:469-476. [PubMed: 22244705]

Sutherland MT, Carroll AJ, Salmeron BJ, Ross TJ, Hong LE, Stein EA. Down-regulation of amygdala and insula functional circuits in abstinent cigarette smokers by varenicline and nicotine. Bio Psychiatry. 2013a

Sutherland MT, Carroll AJ, Salmeron BJ, Ross TJ, Hong LE, Stein EA. Individual differences in amygdala reactivity following nicotinic receptor engagement in abstinent smokers. Neuroimage. $2013 \mathrm{~b}$

Sutherland MT, McHugh M, Pariyadath V, Stein EA. Resting state functional connectivity in addiction: lessons learned and a road ahead. Neuroimage. 2013c

Swart M, Bruggeman R, Laroi F, Alizadeh BZ, Kema I, Kortekaas R, Wiersma D, Aleman A. COMT Val158Met polymorphism, verbalizing of emotion and activation of affective brain systems. Neuroimage. 2011; 55:338-344. [PubMed: 21156209]

Swart M, Kortekaas R, Aleman A. Dealing with feelings: characterization of trait alexithymia on emotion regulation strategies and cognitive-emotional processing. PLoS One. 2009; 4

Takeuchi H, Taki Y, Sassa Y, Hashizume H, Sekiguchi A, Fukushima A, Kawashima R. Regional gray matter density associated with emotional intelligence: evidence from voxel-based mor-phometry. Hum Brain Mapp. 2011; 32:1497-1510. [PubMed: 20740644]

Taylor GJ. Recent developments in alexithymia theory and research. Can J Psychiatry-Rev Can Psychiatr. 2000; 45:134-142.

Taylor GJ, Bagby RM. New trends in alexithymia research. Psychother Psychosom. 2004; 73:68-77. [PubMed: 14767148]

Taylor KS, Seminowicz DA, Davis KD. Two systems of resting state connectivity between the insula and cingulate cortex. Hum Brain Mapp. 2009; 30:2731-2745. [PubMed: 19072897]

Thorberg FA, Young RM, Sullivan KA, Lyvers M. Alexithymia and alcohol use disorders: a critical review. Addict Behav. 2009; 34:237-245. [PubMed: 19010601]

Thorberg FA, Young RM, Sullivan KA, Lyvers M, Connor JP, Feeney GFX. Alexithymia, craving and attachment in a heavy drinking population. Addict Behav. 2011; 36:427-430. [PubMed: 21215527]

Tolmunen T, Heliste M, Lehto SM, Hintikka J, Honkalampi K, Kau-hanen J. Stability of alexithymia in the general population: an 11-year follow-up. Compr Psychiatry. 2011; 52:536-541. [PubMed: 21081227] 
Verdejo-Garcia A, Clark L, Dunn BD. The role of interoception in addiction: a critical review. Neurosci Biobehav Rev. 2012; 36:1857-1869. [PubMed: 22659642]

Wang Z, Faith M, Patterson F, Tang K, Kerrin K, Wileyto EP, Detre JA, Lerman C. Neural substrates of abstinence-induced cigarette cravings in chronic smokers. J Neurosci. 2007; 27:14035-14040. [PubMed: 18094242]

Watson D, Clark LA, Tellegen A. Development and validation of brief measures of positive and negative affect: the PANAS Scales. J Pers Soc Psych. 1988; 54:1063-1070.

Wingbermuhle E, Theunissen H, Verhoeven WMA, Kessels RPC, Egger JIM. The neurocognition of alexithymia: evidence from neuropsychological and neuroimaging studies. Acta Neuropsychiatrica. 2012; 24:67-80.

Zhang X, Salmeron BJ, Ross TJ, Geng X, Yang Y, Stein EA. Factors underlying prefrontal and insula structural alterations in smokers. Neuroimage. 2011; 54:42-48. [PubMed: 20699124]

Ziolkowski M, Gruss T, Rybakowski JK. Does alexithymia in male alcoholics constitute a negative factor for maintaining abstinence. Psychother Psychosom. 1995; 63:169-173. [PubMed: 7624462]

Zubieta JK, Heitzeg MM, Xu YJ, Koeppe RA, Ni LS, Guthrie S, Domino EF. Regional cerebral blood flow responses to smoking in tobacco smokers after overnight abstinence. Am J Psychiat. 2005; 162:567-577. [PubMed: 15741475] 

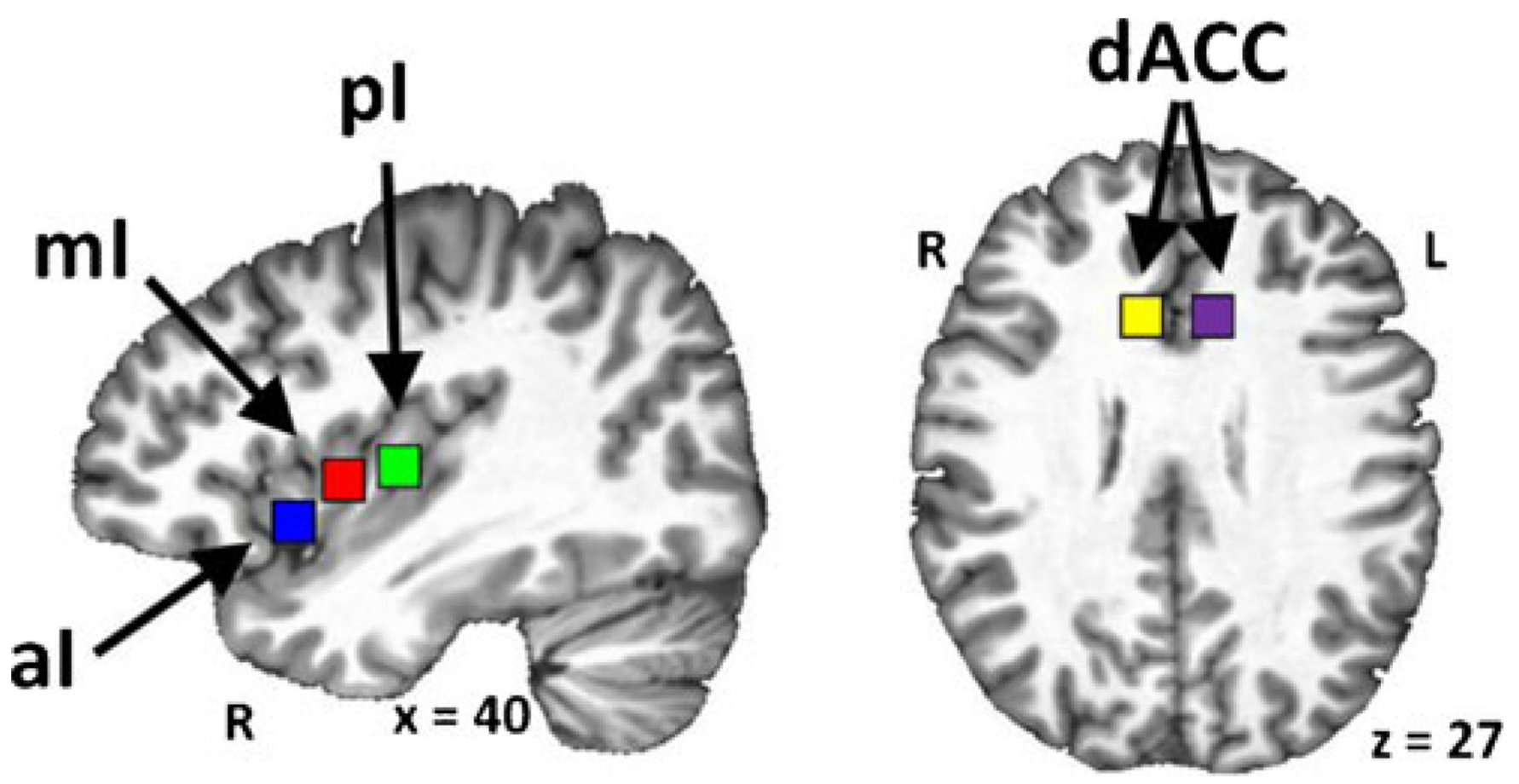

Fig. 1.

Preselected functional connectivity seeds. We used three seeds positioned along a ventralanterior to dorsal-posterior gradient in each hemisphere to interrogate the functional connectivity of insular sub-regions: right/left anterior insula $(a I)$, middle insula $(m I)$, and posterior insula $(p I)$. We also used right/left dorsal ACC $(d A C C)$ seeds to investigate the relation between alexithymia, tobacco craving, and functional connectivity 
al

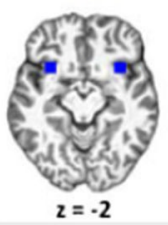

VS.

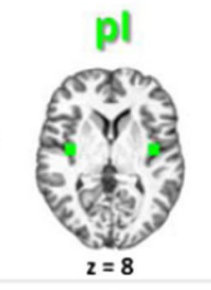

Left

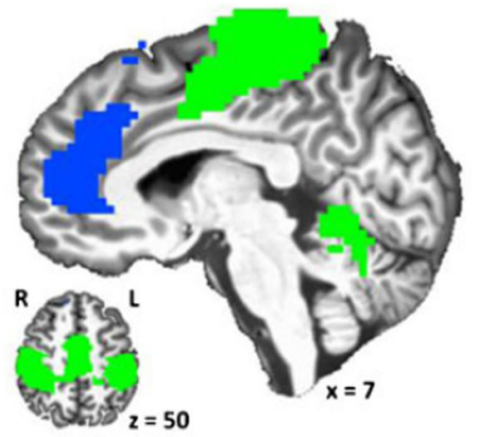

Right

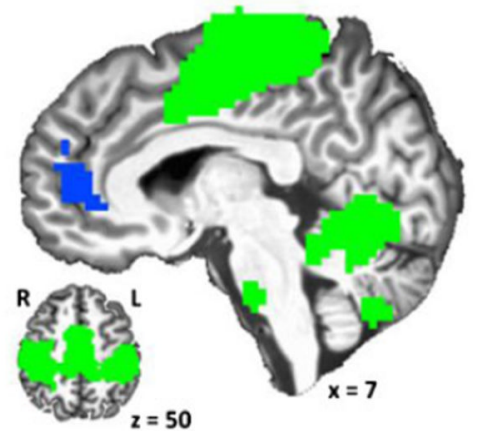

al

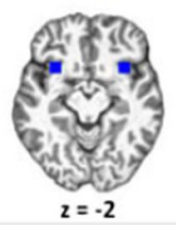

VS.
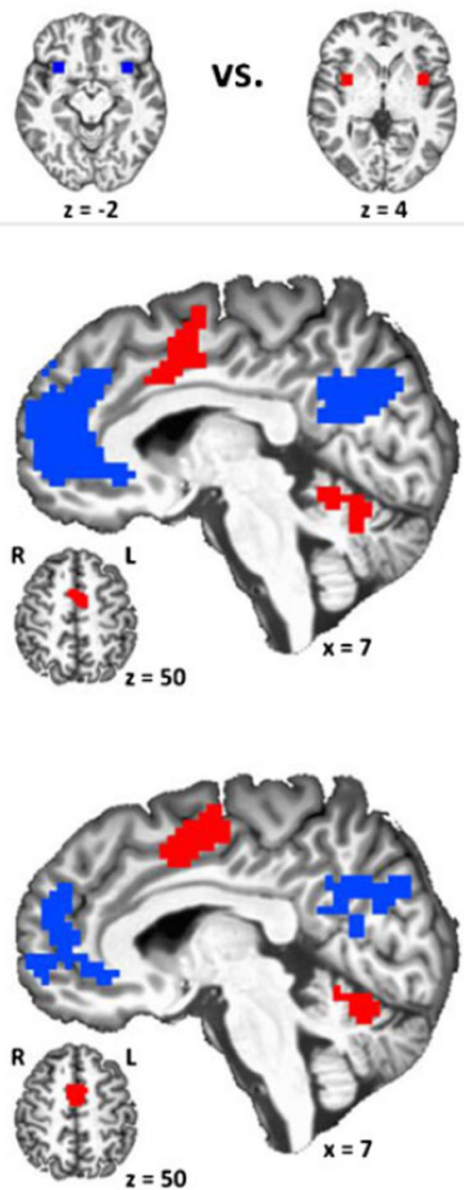

ml

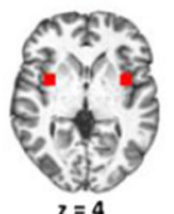

vS.
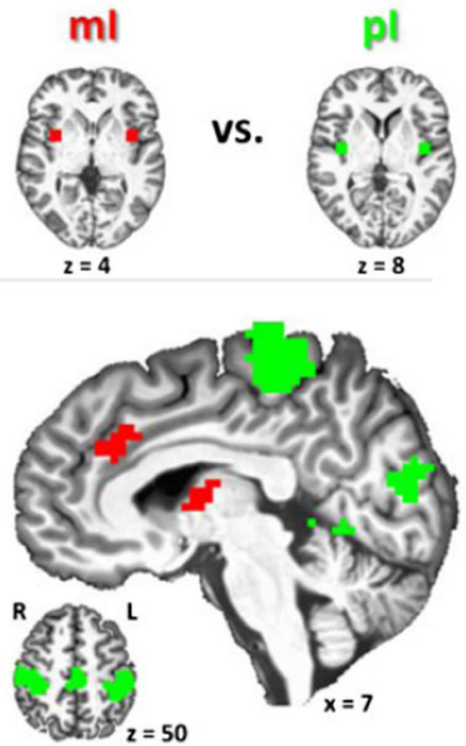

Fig. 2.

Statistical difference maps comparing the functional connectivity of insular subregions. (Left) aI versus pI: aI was more strongly interconnected with pregenual/rostral ACC (blue: $\mathrm{aI}>\mathrm{pI}$ ), whereas $\mathrm{pI}$ showed greater connectivity with mid-cingulate and sensorimotor regions (green: $\mathrm{aI}<\mathrm{pI}$ ). (Middle) aI versus $\mathrm{mI}$ : aI again showed greater connectivity with pregenual/ rostral ACC (blue: aI >mI), whereas $\mathrm{mI}$ was more strongly connected with dACC/presupplemental motor area (red: $\mathrm{aI}<\mathrm{mI})$. (Right) $\mathrm{mI}$ versus $\mathrm{pI}$ : $\mathrm{mI}$ again showed greater connectivity with dACC ( red: $\mathrm{mI}>\mathrm{pI}$ ), whereas pI showed greater connectivity with midcingulate and sensorimotor regions (green: $\mathrm{mI}<\mathrm{pI}$ ). Separate overall $r s F C$ maps from each seed region are shown in Fig. S2 

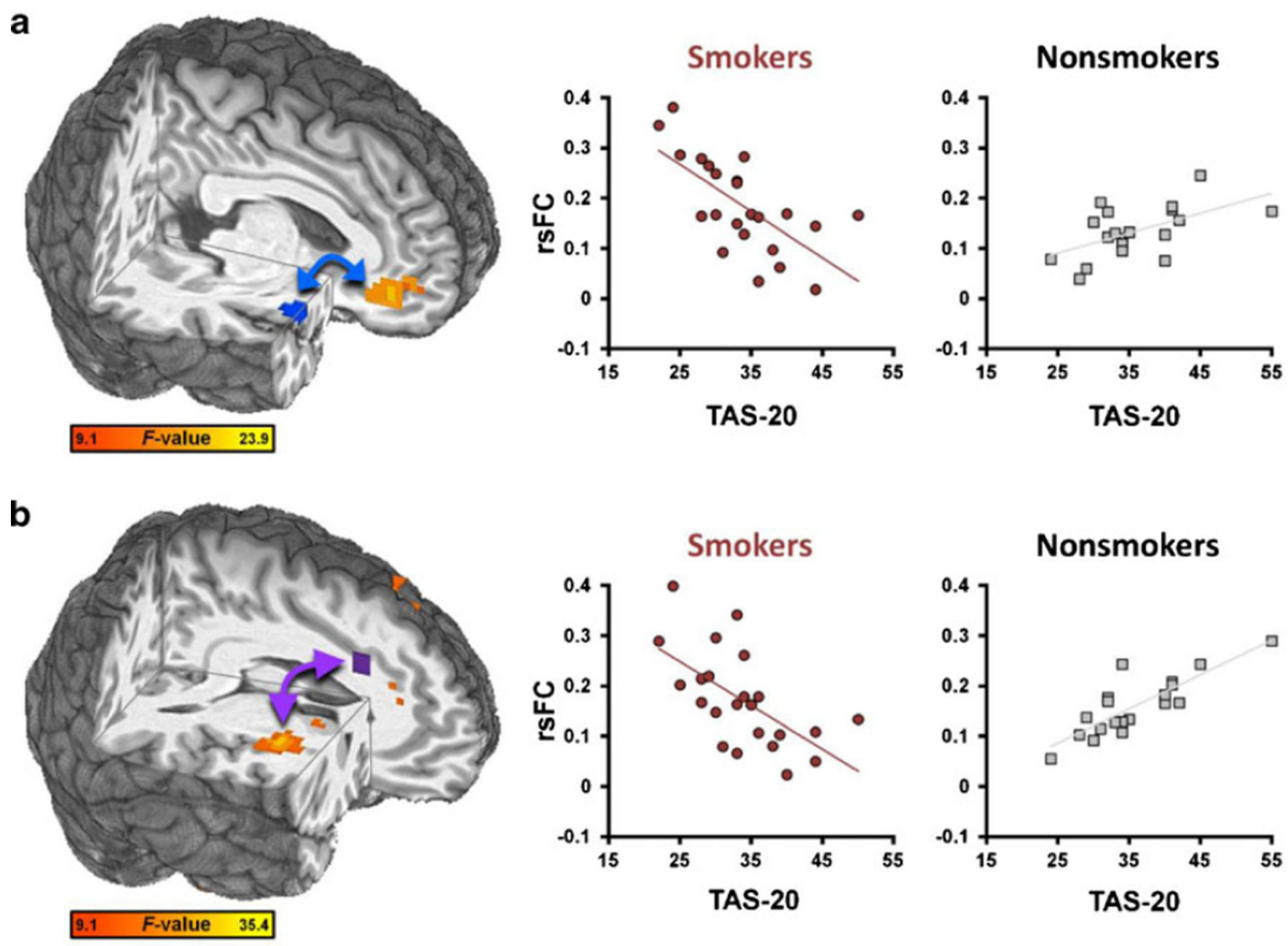

Fig. 3.

Alexithymia differentially predicted session-averaged functional connectivity strength in right insula circuitry when considering smokers versus nonsmokers. (a) Awhole-brain GROUP $\times$ ALEX interaction indicated that $\mathrm{rsFC}$ between a right ventral-anterior insula seed (aI: blue) and vmPFC was differentially associated with TAS-20 scores in smokers versus nonsmokers. Higher TAS-20 scores indicated decreased connectivity strength in the aIvmPFC circuit of smokers but not in nonsmokers. (b) Similarly, a GROUP $\times$ ALEX interaction indicated that rsFC between a left dorsal ACC seed (purple) and right dorsalanterior insula was differentially associated with TAS-20 scores in smokers versus nonsmokers. See Table S2 for coordinates 
a

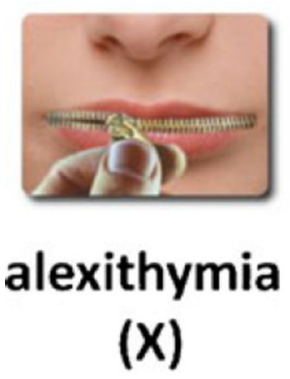

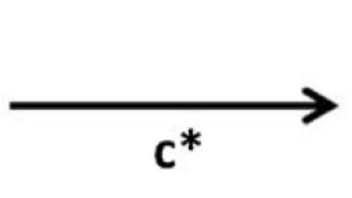

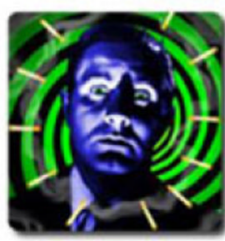

craving

(Y)

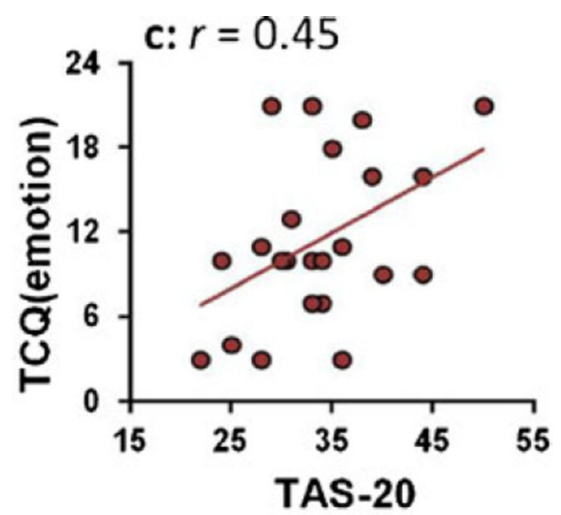

b

(M)
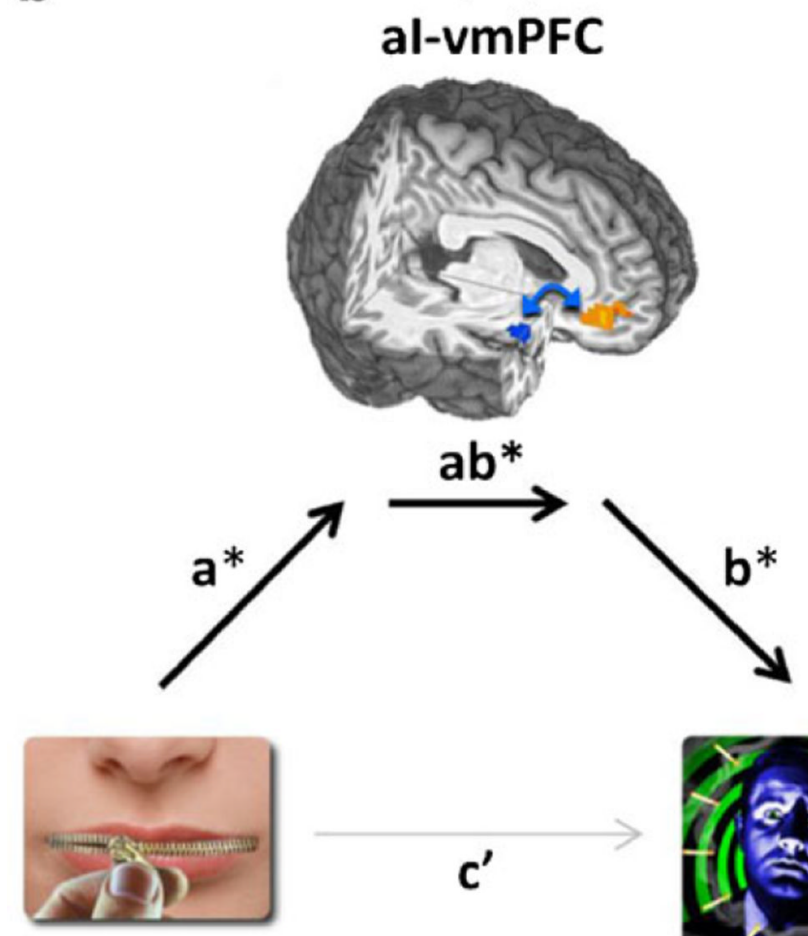

alexithymia

(X)
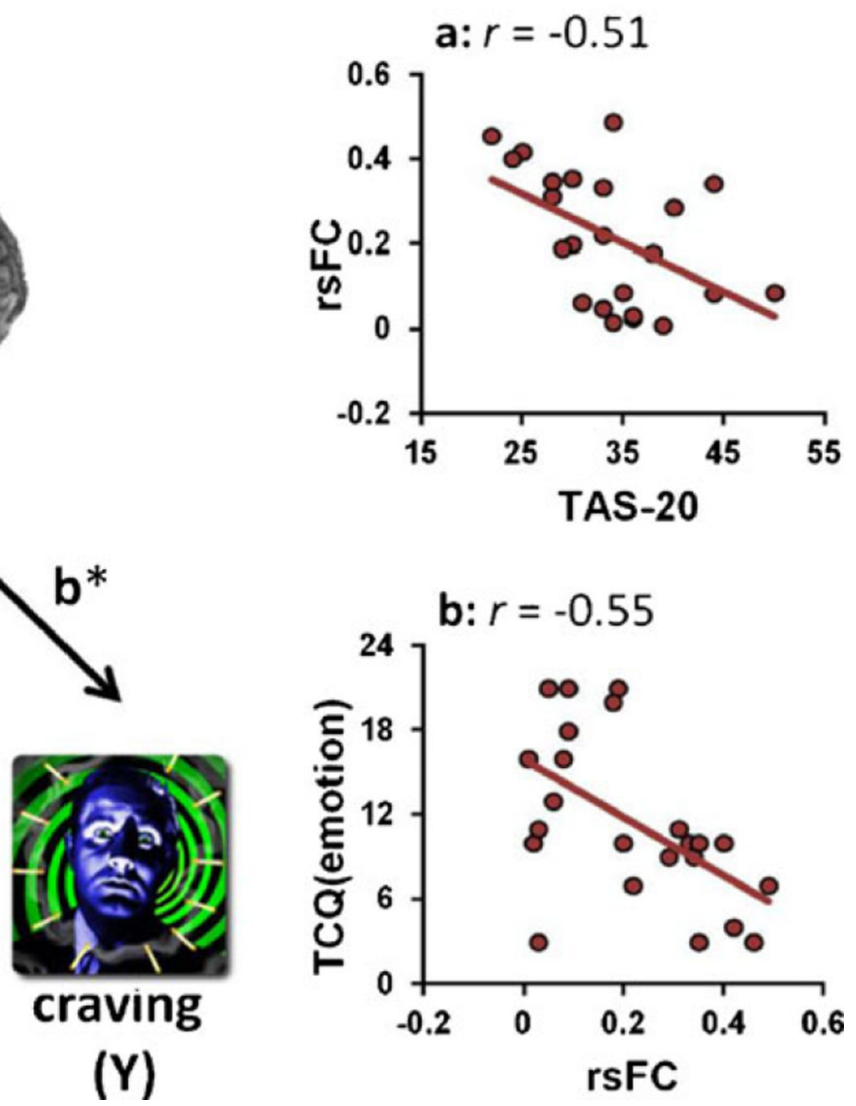

Fig. 4.

Mediation model of the relation between trait alexithymia, state tobacco craving, and session-specific aI-vmPFC functional connectivity during nicotine withdrawal. (a) TAS-20 scores were positively correlated with TCQ-emotionality ratings, i.e., the total effect of alexithymia $(X)$ on craving $(Y)$ was significant (c path). (b) Connectivity strength in the aIvmPFC circuit $(M)$ fully mediated the effect of alexithymia $(X)$ on craving $(Y)$ as: (1) TAS-20 scores accounted for significant variance in aI-VmPFC rsFC (a path); (2) aIvmPFC rsFC accounted for unique variance in TCQ ratings when controlling for TAS-20 (b path); (3) the indirect mediation effect was significant (ab path); and (4) alexithymia's direct 
effect on craving was no longer significant when the aI-vmPFC mediator was included in the model (c' path). See Table S3 for path coefficient values. ${ }^{*} p<0.05$ 